\title{
Factors modulating superoxide dismutase activity in needles of spruce trees (Picea abies L.)
}

\author{
A. Polle ${ }^{1}$, B. Krings ${ }^{2}$ and H. Rennenberg ${ }^{1}$ \\ 1 Fraunhofer Institut für Atm. Umweltforschung, Kreuzeckbahnstr. 19, D-8100 Garmisch-Partenkir- \\ chen, and \\ 2 Botanisches Institut der Universität zu Köln, Gyrhofstr. 15, D-5000 Köln 41, F.R.G.
}

\section{Introduction}

Superoxide dismutases (SOD) are considered to be a major enzymic defense against oxygen toxicity in cells (Fridovich, 1986). These enzymes contain either $\mathrm{Cu} / \mathrm{Zn}, \mathrm{Mn}$ or $\mathrm{Fe}$ in their catalytic center (Fridovich, 1986). Most abundant in plants are Cu/Zn-SODs which are characterized by a broad $\mathrm{pH}$-optimum between $\mathrm{pH} 7$ and $\mathrm{pH} 10$ and an inhibition by cyanide and $\mathrm{H}_{2} \mathrm{O}_{2}$ (Fridovich, 1986). SODs detoxify superoxide radicals originating from physiological functions, such as photosynthesis under excess light energy (Robinson, 1988), as well as different environmental stress factors, such as herbicides and air pollutants $\left(\mathrm{O}_{3}, \mathrm{SO}_{2}, \mathrm{NO}_{2}\right)$ (Rabinowitch and Fridovich, 1983; Fridovich, 1986). Since it is generally assumed that air pollution is one of the major reasons for forest decline in Central Europe, we compared SOD activity in needles of healthy and injured spruce trees growing in the field.

\section{Materials and Methods}

Experiments were performed with needles from Nonway spruce trees (Picea abies L.) growing in the field. Extracts of spruce needles were prepared as described elsewhere (Polle et al., 1989). After dialysis, the activity of superoxide dismutase was determined according to the method of Misra and Fridovich (1972). This assay is based on the autooxidation of epinephrine to adrenochrome at $\mathrm{pH} 10.2 . \mathrm{O}_{2}^{-}$serves as the chain-propagating species in this reaction. SOD competes for $\mathrm{O}_{\overline{2}}^{-}$, thus inhibiting adrenochrome formation. By definition, 1 unit of SOD is the amount of extract that inhibits the maximal rate of adrenochrome formation by $50 \%$.

\section{Results}

To determine SOD activity, we adapted extraction and assaying procedures (after Misra and Fridovich, 1972) to extracts from spruce needles (Polle et al., 1989). Fig. 1 shows a typical calibration curve for spruce SOD. Increasing amounts of spruce extract exhibited increasing inhibition of adrenochrome formation with a saturation level of $80 \%$. In comparison with spruce extract, a commercially available SOD preparation from horseradish reached a saturation level of $90 \%$ in this assay system (not shown). The failure to obtain complete inhibition was attributed 


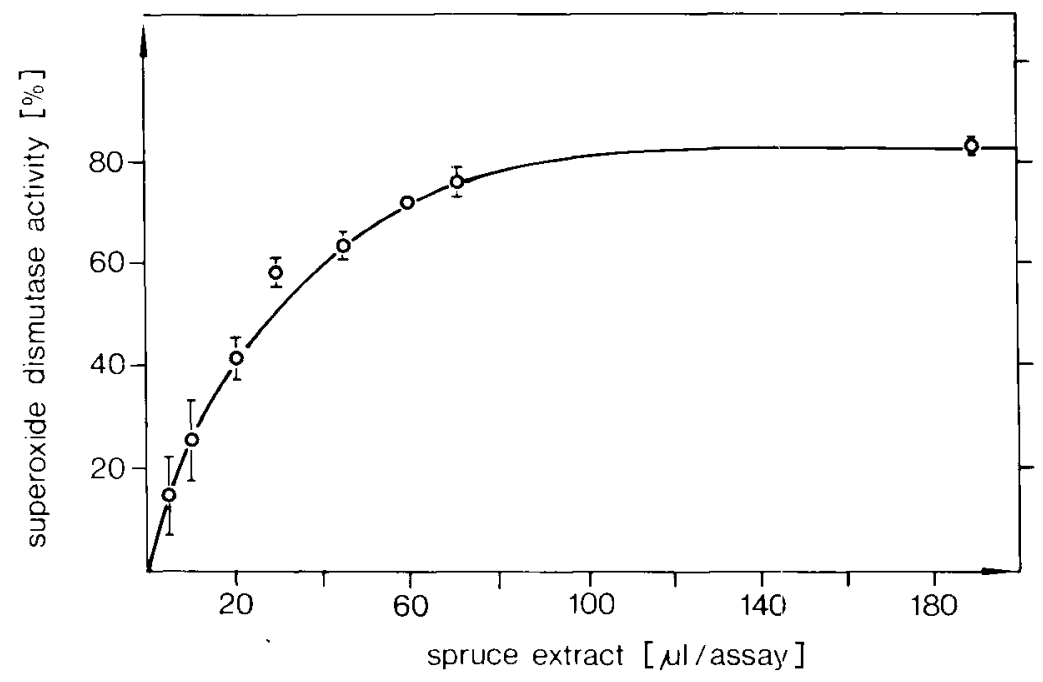

Fig. 1. SOD activity in extracts of spruce needles. One unit of SOD corresponded to $27 \mu$ of extract in a total assay volume of $1 \mathrm{ml}$. The extract contained a protein concentration of $0.6 \mathrm{mg} / \mathrm{ml}, n=5$, bars represent standard error.

to alternative oxidative pathways (Misra and Fridovich, 1972; Fridovich, 1986). possibly caused by interacticiss with other components present in crude dialyzed spruce extracts.

In the presence of cyanide $(20 \mu \mathrm{M}$ $\mathrm{NaCN}$ ), the inhibition of adrenochrome formation was completely blocked (not shown). This observation indicates that predominately $\mathrm{Cu} / \mathrm{Zn}$-containing SODspecies contributed to the activity determined with the epinephrine assay.

It has been reported for other plants that the activity of SOD is dependent upon the developmental stage of the tissue analyzed (Rabinowitch and Fridovich, 1983). However, data on developmentally determined changes in SOD activity in needles of conifers have not been published. Therefore, the activity of SOD was analyzed in 4 subsequent generations of needles of healthy trees and compared with the activity in needles of injured trees with $50 \%$ loss of needles.
In needles from healthy trees, SOD activity was highest in the youngest needles and then declined by about $25 \%$ in $4 \mathrm{yr}$ old needles. In needles from injured trees, an enhanced level of SOD activity was maintained through the 4 needle generations studied.

\section{Discussion}

Enhanced activity of superoxide dismutase in younger leaves has previously been reported in several plant species (Rabinowitch and Fridovich, 1983) and was accompanied by an enhanced tolerance against $\mathrm{SO}_{2}$ (Tanaka and Sugahara, 1980). Furthermore, higher SOD activities were found in conifer needles after ozone fumigation (Castillo et al., 1987) or if the trees were growing in $\mathrm{SO}_{2}$-polluted regions (Huttunen and Heiska, 1988). We observed in healthy needles of spruce trees growing in the field that SOD activity 


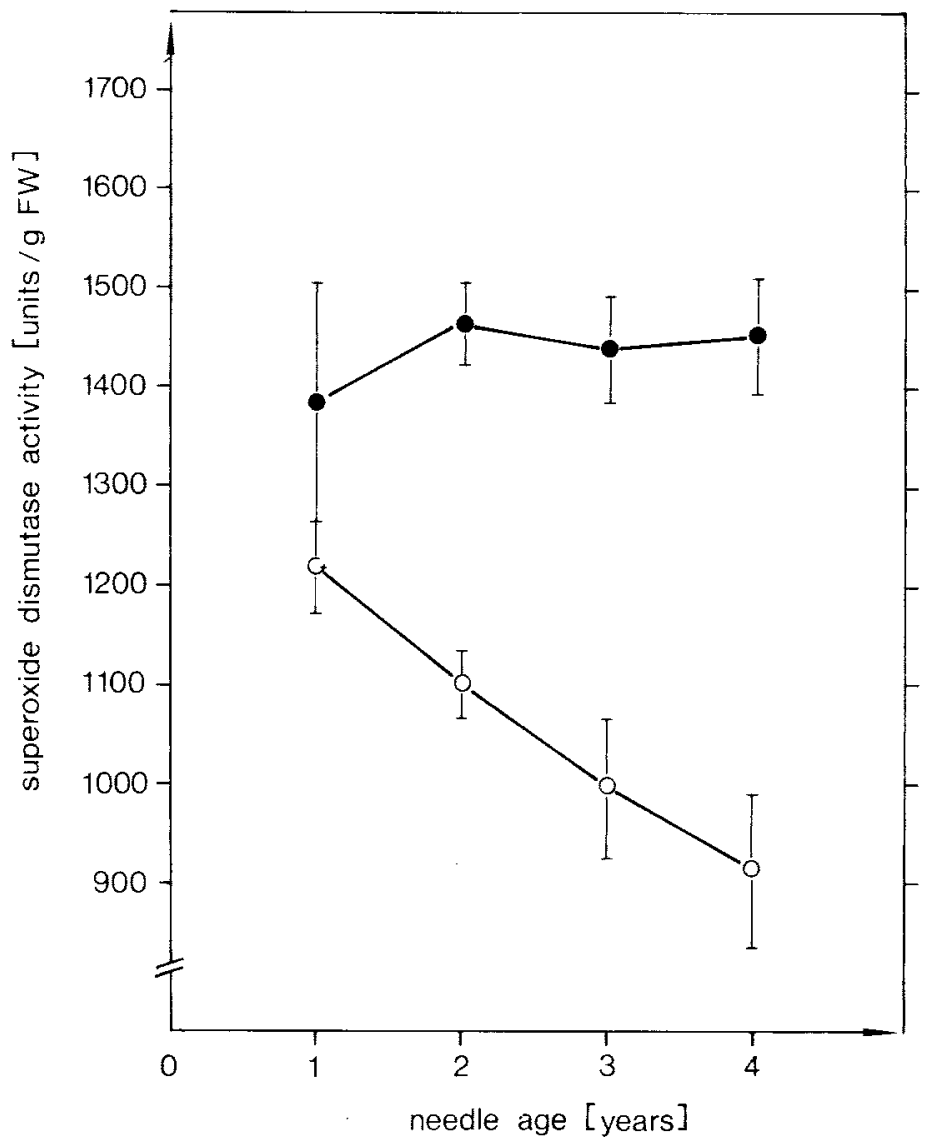

Fig. 2. SOD activity as a function of needle age and habitus of the tree. Needles of the same age from 4 trees were mixed and used for the determination of SOD activity in needles of 'healthy' (O) and 'injured' (O) trees. $n=4$, bars represent standard error.

showed a maximum in the youngest needles and then declined. In young needles of severely injured trees, the SOD activity was slightly enhanced as compared to SOD activity in needles from healthy trees. This high level of SOD activity was maintained in the 4 needle generations analyzed. This result suggests, that among other factors, SOD activity in young needles is determined by intrinsic developmental factors, while in older needles, external environmental trig- gering mechanisms, such as, perhaps, air pollution, play a major role in the regulation of SOD activity.

\section{Acknowledgments}

We thank Beate Huber and Monika Braun for expert technical assistance and acknowledge financial support from the Bundesminister für Forschung und Technologie under contract no. $0339019 \mathrm{~B} 7$. 


\section{References}

Castillo F.J., Miller P.R. \& Greppin H. (1987) Waldsterben Part IV. Extracellular biochemical markers of photochemical oxidant air pollution damage to Norway spruce. Experientia 43, 111115

Fridovich I. (1986) Superoxide dismutases. Adv. Enzymol. 58, 61-97

Huttunen S. \& Heiska E. (1988) Superoxide dismutase activity in Scots pine (Pinus sylvestris L.) and Norway spruce (Picea abies L.) needles in northern Finland. Eur. J. For. Pathol. 18, 343350

Misra H.P. \& Fridovich I. (1972) The role of superoxide anion in the autooxidation of epine- phrine and a simple assay for superoxide dismutase. J. Biol. Chem. 247, 3170-3175

Polle A., Krings B. \& Rennenberg H. (1989) Superoxide dismutase activity in needles of Norwegian spruce trees (Picea abies L.). Plant Physiol. 90, 1310-1316

Rabinowitch H.D. \& Fridovich I. (1983) Superoxide radicals, superoxide dismutases and oxygen toxicity in plants. Photochem. Photobiol. 37, 679-690

Robinson J.M. (1988) Does $\mathrm{O}_{2}$ photoreduction occur within chloroplasts in vivo? Physiol. Plant. 72, 666-680

Tanaka K. \& Sugahara K. (1980) Role of superoxide dismutase in defense against $\mathrm{SO}_{2}$ toxicity and an increase in superoxide dismutase activily with $\mathrm{SO}_{2}$ fumigation. Plant Cell Physiol. 21, 601-611 